\title{
O NOVO QUALIS PERIÓDICOS Possíveis diretrizes, impactos e resistências
}

\author{
Olivia Cristina Perez \\ Universidade Federal do Piauí \\ Departamento de Ciências Políticas | Teresina, Brasil \\ Editora Associada da Revista Brasileira de Ciências Sociais (RBCS) \\ 889oliviaperez@gmail.com | ORCID iD: 0000-0001-9441-7517
}

A

estratificação dos periódicos no Brasil é feita pelo chamado sistema Qualis Periódicos, criado pela

Coordenação de Aperfeiçoamento de Pessoal de Nível

Superior (CAPES). Nesse sistema, os periódicos das diversas áreas do conhecimento são classificados em estratos A1, A2, B1, B2, B3, B4, B5 e C, em ordem decrescente, conforme a sua relevância.

Embora o Qualis avalie a qualidade da produção intelectual dos programas de pós-graduação brasileiros, e por isso exerça influência imediata sobre as notas dos programas, ele também tem efeito sobre a carreira dos pesquisadores e a possibilidade de que os estudantes deem continuidade à sua formação. Por isso a reflexão sobre o sentido dos critérios adotados no Qualis é central para a academia brasileira.

Esse sistema de classificação está em discussão atualmente. Notícias dão conta de que em algum momento no futuro o sistema adotará a mesma métrica para classificar os periódicos nacionais e internacionais, o que prejudicaria os periódicos brasileiros, afetando todo o sistema educacional que os tem como meios de publicação. Em face desse problema algumas ações estão sendo organizadas como alternativa ao novo modelo do Qualis.

Com o propósito de contribuir para o debate, este texto tem quatro objetivos: 1) elencar algumas das possíveis mudanças indicadas pela Capes no tocante à avaliação dos periódicos; 2) apontar possíveis impactos para as revistas e para os programas 
de pós-graduação; 3) apresentar resistências ao novo Qualis; 4) tecer algumas considerações sobre o aprofundamento das desigualdades regionais que o novo sistema de classificação pode vir a provocar.

As informações elencadas neste texto são derivadas de comunicações oficiais da CAPES e de experiências pessoais em reuniões que tratam da avaliação dos periódicos. No entanto, como as informações sobre as mudanças atuais ainda não são oficiais, tampouco permanentes, trata-se de um texto que procura esboçar algumas considerações, no sentido de estimular o debate sobre a avaliação dos periódicos brasileiros.

\section{Mudanças no Qualis Periódicos}

O Qualis Periódicos se orienta atualmente de acordo com os extratos divulgados em 2017 na página da Capes referentes ao quadriênio de 2012 a 2016. É por esse sistema de avaliação que os pesquisadores vêm se guiando.

Esse sistema tem sido alvo de diversas críticas, especialmente porque um periódico bem avaliado em determinada área pode ser mal avaliado em outra. De acordo com o critério vigente, um pesquisador que publica em uma área diferente da área de avaliação de seu programa de pósgraduação pode ser prejudicado. Além disso, professores que estão vinculados há dois ou mais programas de pós-graduação têm de planejar a submissão de artigos com a perspectiva de que seu currículo se beneficie de avaliações favoráveis em áreas distintas. Essa situação é comum em universidades com menos doutores e menos professores, tais como aquelas situadas em regiões mais periféricas. A atribuição de notas distintas entre as áreas também gera problemas em concursos públicos, o que tem levado a processos judiciais, dado que alguns candidatos não consideram justo suas boas publicações não terem tanto peso na área do concurso.

Para contornar essas e outras críticas ao sistema de classificação dos periódicos e, talvez, guiados por outros interesses, a Capes começou a discutir a possibilidade de um Qualis único que fosse válido para todas as áreas. O chamado Qualis Referência qualificaria a produção acadêmica a partir de uma classificação única de cada periódico atribuída por uma área-mãe. Indicadores bibliométricos seriam utilizados para a definição da posição dos periódicos dentro de cada estrato. 
De acordo com essa nova proposição, as áreas fizeram ainda em 2019 uma simulação inicial que continha a qualificação atribuída a todos os periódicos. $\mathrm{O}$ documento que resultou dessa iniciativa não era oficial, mas foi divulgado informalmente e ficou conhecido como Qualis Referência ou como "Qualis vazado".

O Qualis Referência foi objeto de muita controvérsia, em especial a respeito dos critérios que seriam adotados por distintas áreas para avaliar seus periódicos. As discussões sobre o sistema de avaliação dos periódicos continuaram e ainda hoje, em novembro de 2020, não se sabe qual será a classificação válida para a avaliação dos programas de pós-graduação.

No caso das Ciências Humanas, coube ao Grupo de Trabalho intitulado Qualis de Humanidades definir regras gerais para a grande área que poderiam ter certa flexibilidade segundo as especificidades dos campos de saber. Em março de 2020, o GT Qualis de Humanidades recomendou que o Qualis Periódicos do Colégio de Humanidades se baseasse em indexadores tais como o CiteScore (Scopus), fator de impacto (FCR/Web of Science) ou índice h (Google Scholar), utilizados de forma isolada ou combinada a depender do perfil da área, prevendo inclusive a definição de subáreas de conhecimento e de idioma/origem de publicação (Colégio das Humanidades 2020). Dessa discussão resultou a proposição dos modelos QR2 - Qualis Referência H e QR3 - Qualis Referência Três Percentis que anteviam o uso do índice $\mathrm{h}$ somente para a definição do percentil ou para a possibilidade de aplicação do maior percentil entre os três determinados pelos indexadores CiteScore, Fator de Impacto e H5 (idem).

Em julho de 2020, na $1^{\text {a }}$ Reunião Extraordinária do Conselho Técnico-Científico da Educação Superior (CTC-ES), o modelo do Qualis Referência foi aprovado, o que resultaria na adoção de índices bibliométricos para a definição dos estratos condicionada a cálculos adequados às diferentes áreas (Coordenação de Aperfeiçoamento de Pessoal de Nível Superior 2020). Conforme o Ofício da Capes, as Ciências Exatas (todas, exceto o Ensino) e Ciência da Vida (todas, exceto a Saúde Coletiva) seriam avaliadas pelo uso combinado de indicadores bibliométricos e de um modelo matemático. Para as áreas do Colégio de Humanidades, do Ensino e da Saúde Coletiva, seria utilizado principalmente o índice $\mathrm{h}$, que permitiria dividir a avaliação segundo as subáreas e os idiomas dos periódicos e garantiria desse modo uma diferenciação interna segundo as 
especificidades das áreas. Além disso, haveria a possibilidade de ajustes dentro de cada área-mãe: até $20 \%$ dos estratos poderiam ser alterados em um nível (para cima ou para baixo) e até $10 \%$ dos estratos poderiam ser alterados em dois níveis (para cima ou para baixo). (idem).

No entanto essa não era uma decisão final e os critérios para a avaliação tomaram outros rumos que por vezes resultaram no oposto das decisões anteriores. No início de setembro ocorreu a $198^{a}$ reunião ordinária do CTG-ES, que deliberou que os periódicos de humanidades não seriam mais subdivididos por idioma e origem da publicação e deixou aberta a eventual possibilidade de agrupamento pelo modelo QR3 (Colégio das Humanidades 2020). Uma vez que não haveria distinção entre os países e os idiomas de origem dos periódicos, os periódicos brasileiros não seriam tão bem avaliados quanto os periódicos internacionais. Como contrapeso à decisão geral, aventou-se a possibilidade de ajustes de alguns periódicos para estratos mais elevados, mas a determinação dos casos em que esse ajuste poderia acontecer resultou arbitrária. Os pesquisadores passaram então a questionar os impactos desse novo sistema de classificação.

\section{Possíveis impactos com a adoção do novo Qualis}

O Qualis Periódico avalia a produção intelectual dos programas de pós-graduação e por isso influencia a nota dos programas. Notas mais altas possibilitam o repasse de recursos para o programa, inclusive para seus docentes e discentes. Mas quando o sistema de avaliação quadrienal confere uma nota baixa ao programa, ele é prejudicado a ponto de obrigar as administrações a dissolvê-lo, o que compromete a possibilidade de que os futuros pesquisadores da respectiva área continuem seus estudos. Considerando o impacto social da ciência, a falta de um programa de pós-graduação em determinada área também traz consequências negativas para o desenvolvimento de uma região.

Embora o sistema Qualis não classifique a produção individual, a carreira do pesquisador é influenciada por ele. Os pesquisadores com produção em periódicos mais bem qualificados têm mais chances de obter bolsas de pesquisas e, com isso, de consolidar sua carreira. Logo, o Qualis exerce uma influência decisiva sobre os programas de pós-graduação, a 
carreira dos pesquisadores e a própria possibilidade de desenvolvimento de determinada região.

A falta de definição sobre o Qualis que contará para a próxima avaliação dos programas de pós-graduação já tem gerado efeitos negativos. O Qualis Referência que foi vazado em 2019, ainda que não fosse oficial, influenciou a escolha dos periódicos por parte dos pesquisadores. Diversos periódicos chegaram até mesmo a declarar nas suas páginas virtuais o novo estrato que receberam pelo Qualis vazado.

Uma das consequências mais preocupantes em relação ao Qualis tem relação com o timing das mudanças. A julgar pelo cenário que se desenha, ele será alterado entre o final do ano de 2020 e o início de 2021, passando a valer para todo o quadriênio. Se o sistema de avaliação realmente for alterado e retroagir sobre o quadriênio passado, muitos artigos submetidos a periódicos que eram considerados bem avaliados não serão mais.

Outro problema é a classificação dos periódicos brasileiros. Se o Qualis utilizar a mesma métrica para classificar os periódicos nacionais e internacionais, certamente os periódicos brasileiros ficarão com notas mais baixas, considerando que seus índices de citação são infinitamente menores que os de grande parte das revistas estrangeiras. As revistas brasileiras poderiam deixar de ser atraentes para os pesquisadores, que então submeteriam suas pesquisas a periódicos internacionais. A baixa atratividade dos periódicos brasileiros poderia prejudicar toda a agenda de pesquisa brasileira, pois os pesquisadores teriam que redirecionar suas linhas de investigação de acordo como os interesses das revistas internacionais, abordando questões dos países dos periódicos em vez das questões locais.

As mudanças no Qualis afetariam também a carreira dos pesquisadores. A adoção da mesma métrica para revistas nacionais e internacionais geraria uma competição ainda maior, já que os brasileiros teriam de competir com pesquisadores de todo o mundo. Essa competição agravaria o excesso de trabalho dos pesquisadores brasileiros, que já estão encarregados com ensino, extensão e gestão das universidades. A qualificação maior das revistas estrangeiras também poderia privilegiar autores e programas que já estão inseridos internacionalmente, comprometendo os programas com menos recursos e com mais dificuldades de internacionalização. 
Pode-se argumentar que se todos os periódicos brasileiros ficarem com qualificação baixa, não haverá impacto na avaliação dos programas de pós-graduação, já que todos igualmente teriam suas notas reduzidas. No entanto, para que um programa seja considerado de excelência, espera-se que seus pesquisadores publiquem em revistas internacionais e altamente qualificadas. Se certos programas de determinadas áreas, como no caso das Ciências Sociais, não atingirem esse nível, pode ser que suas notas não alcancem os critérios de excelência, dificultando a já escassa obtenção de recursos.

Em última instância, o que está em jogo é a própria sobrevivência das Ciências Humanas. Caso sejam medidas pela mesma métrica aplicada às outras áreas sem distinção dos idiomas e origens das revistas, as Ciências Humanas podem ter classificações mais baixas, o que contribuiria ainda mais para seu estrangulamento.

\section{Algumas resistências ao novo Qualis}

Os próprios Coordenadores da área de Humanidades expressaram surpresa e descontentamento em relação às novas mudanças aventadas pela Capes. Em carta dirigida ao presidente da Capes, do CTC-ES e ao Senhor Presidente, no dia 14 de outubro de 2020 (Colégio das Humanidades 2020) o Colégio de Humanidades solicitou a revogação das deliberações anteriores, em especial aquelas tomadas pelo CTCES em sua $198^{a}$ reunião ordinária. Os coordenadores solicitaram também o reestabelecimento do QR3 como uma forma alternativa de agrupamento dos indicadores e de possibilidade de subdivisões por idioma/origem dos periódicos. O Colégio de Humanidades defende que a avaliação dos periódicos, ainda no quadriênio 2017-2020, reflita as produções da pós-graduação brasileira a partir das características das áreas.

Muitas associações estão se organizando para discutir e propor ações que venham a garantir um modelo de classificação dos periódicos baseado nas especificidades de cada área. Por exemplo, o próximo encontro da Associação Nacional de PósGraduação e Pesquisa em Ciências Sociais (ANPOCS) em dezembro deste ano contará com discussões sobre o futuro do Qualis, como a atividade intitulada "O futuro dos periódicos".

Outra instituição que vem promovendo esse debate é o Fórum de Ciências Humanas e Sociais e Sociais Aplicadas, Letras e Artes (FCHSSALA), responsável por articular as diversas 
sociedades científicas que compõem essa grande área do conhecimento do Sistema Nacional de Ciência e Tecnologia brasileiro. No dia 23 de outubro de 2020, o ex-coordenador do Fórum, Luciano Mendes de Faria Filho, escreveu um texto intitulado "Qual o destino da Pós-Graduação e da Pesquisa nas Humanidades?", denunciando o ataque à autonomia das Humanidades pela Capes, que estaria inclusive quebrando acordos anteriormente assinados e aprovados pelas instâncias colegiadas da Agência (Faria Filho 2020). Conforme Faria Filho (2020), o desrespeito aos acordos estabelecidos e a adoção de um modelo de avaliação que traria consequências desastrosas para as ciências humanas seriam as principais características das ações promovidas pela Capes e por parte significativa da comunidade acadêmica. Em última instância o ataque às ciências humanas faria parte do projeto representado pelo atual presidente Jair Bolsonaro, que desqualifica as ciências em geral e as ciências humanas em particular.

Esse não é um ataque fortuito. As ciências humanas promovem a reflexão, inclusive sobre o projeto político em curso. A reflexão é a base de toda ciência, inclusive nas áreas das exatas e da saúde. Nesse sentido o ataque às ciências humanas é um ataque à ciência em geral.

\section{Considerações finais: acirramento das desigualdades regionais}

Todas essas consequências negativas da adoção do novo Qualis seriam ainda mais drásticas pensando em programas de pós-graduação e em pesquisadores que estão em universidades periféricas. A prática demonstra que já existe uma resistência em relação à publicação de estudos de caso ou aos temas pertinentes às regiões com pouca inserção no circuito acadêmico. Quando esses temas têm algum espaço, essas pesquisas são publicadas em revistas também situadas em regiões periféricas ou que dialogam com tais contextos. Nas revistas internacionais essas pesquisas teriam pouco espaço. As próprias revistas dessas regiões não teriam como sobreviver, já que não atrairiam pesquisadores e tampouco recursos.

A dificuldade de publicação de pesquisas que tratem dos temas locais das regiões mais periféricas prejudicaria as notas dos programas de pós-graduação. Embora a Capes também tenha reformulado a ficha de avaliação dos programas de pósgraduação, dando maior importância à inserção e ao impacto 
regional, a importância da publicação para as notas dos programas de pós-graduação é inegável. Se o sistema do novo Qualis criar mais dificuldades para a publicação em periódicos qualificados, o desempenho dos programas segundo os novos critérios certamente será inferior ao atual.

Em geral os projetos políticos que defendem a redução do investimento estatal acabam prejudicando aqueles grupos e instituições que já são mais pobres e assim alimentam os ciclos das desigualdades. Esse perverso mecanismo aparentemente vai se repetir na avaliação dos programas de pós-graduação das regiões periféricas. Daí a necessidade de esclarecimentos e reflexões sobre o futuro da ciência e do desenvolvimento do nosso país.

\section{Referências Bibliográficas:}

COLÉGIO DAS HUMANIDADES. 2020. Carta do Colégio das Humanidades ao Presidente da CAPES. Brasília, 14 de outubro de 2020. Disponível em: http://pensaraeducacao.com.br/blogpensaraeducacao/wp content/uploads/sites/6/2020/10/Carta_Humanidades_ Presidente_CAPES-1.pdf. Acesso em 04 de novembro de 2020.

COORDENAÇÃO DE APERFEIÇOAMENTO DE PESSOAL DE NÍVEL SUPERIOR. 2020. Oficio Circular $n^{\circ}$ 31/2020-GAB/PR/CAPES. Brasília, 24 de julho de $2020 . \quad$ Disponível em: http://uploads.capes.gov.br/files/OF_GIRGULAR_312020-GAB-PR-CAPES.pdf. Acesso em 04 de novembro de 2020.

FARIA FILHO, Luciano Mendes de. 2002. Qual o destino da PósGraduação e da Pesquisa nas Humanidades? Divulgado em 23 de outubro de 2020. Disponível em: https://pensaraeducacao.com.br/blogpensaraeducacao/c arta-do-colegio-das-humanidades-ao-presidente-da-capes/. Acesso em 04 de novembro de 2020.

Enviado: 20 de novembro de 2020 Aceito: 5 de dezembro de 2020 